\title{
EXPERIMENTAL STUDY ON GEOPOLYMER CONCRETE BY USING GGBS
}

\author{
Paras S.Pithadiya ${ }^{1}$, Abhay V. Nakum ${ }^{2}$ \\ ${ }^{1} P G$ Student, Marwadi Education Foundation, Gujarat, India \\ ${ }^{2}$ Assistant Professor, Civil Engineering Department, Marwadi Education Foundation, Gujarat, India
}

\begin{abstract}
The demand of concrete is increasing day by day and Cement is used for satisfying the need of development of infrastructure facilities, 1 tone cement production generates 1 tone CO2, which adversely affect the environment. In order to reduce the use of OPC and CO2 generation, the new generation concrete has been developed such as GEOPOLYMER CONCRETE. It uses Fly ash and Alkaline Solution as their Binding Materials. Geopolymer requires Oven Curing in the varying range of 60C to $100 \mathrm{C}$ for a period of 24 to 96 hours.
\end{abstract}

The objective of the present work is to study the effect of GGBS in fly ash based Geopolymer concrete and to study the Effect of Oven Curing and Ambient room temperature curing on them. And By replacing fly ash from 0 to $100 \%$ with GGBS and inspecting the Fresh Properties and Hardened Concrete properties at 7 days. The casted cube will be cured at normal room temperature and at $70^{\circ} \mathrm{C}$ Oven heat provision for 24 hours and to ascertain the behavior of concrete mixed with GGBS, thereby examining the changes of properties like Strength and Durability.

Keywords: Fly ash, GGBS, Alkaline Solution, strength, durability, utilization

\section{INTRODUCTION}

Concrete is one of the most widely used construction materials and the Portland cement is a main component for making concrete. Concrete usage around the world is second only to water. Ordinary Portland cement (OPC) is conventionally used as the primary binder to produce concrete. The production of cement generates large amount of carbon dioxide. Carbon dioxide could be reduced if the production of cement could be reduced. The production of one ton of cement emits approximately one ton carbon dioxide to the atmosphere, which leads to global warming conditions. So, one of the ways to produce environmentally friendly concrete is to reduce the use of Ordinary Portland Cement by replacing cement with by-product materials such as fly ash. One of the efforts to produce more environmentally friendly concrete is to replace the Portland cement in concrete with by-product materials such as fly ash. An effort to make environmentally friendly concrete is the development of inorganic alumina-silicate polymer, such as fly ash that are rich in silicon and aluminum called Geopolymer, synthesized from materials of geological origin or by-product materials such as Fly ash that are rich in Silicon and Aluminum.

GGBS (Ground Granulated Blast Slag) is a waste material Generated in iron or Slag Industries have significant impact on Strength and Durability of Geopolymer Concrete.

\section{LITERATURE REVIEW}

Several authors have reported the use of GGBS in Geopolymer Concrete for various civil engineering applications.
Palomo , Grutzeck and Blanco [1] investigated the The alkali activation of waste materials. has become an important area of research in many laboratories because it is possible to use these materials to synthesize inexpensive and ecologically sound cement like construction materials. In the present paper, the mechanism of activation of a fly ash (no other solid material was used) with highly alkaline solutions is described. These solutions, made with $\mathrm{NaOH}, \mathrm{KOH}$, water glass, etc., the product of the reaction is an amorphous aluminosilicate gel Mechanical strengths with values in the $60 \mathrm{MPa}$ range were obtained after curing the fly ash at $85 \mathrm{C}$ for only $5 \mathrm{~h}$.

Anurag, Deepika [2] and his fellows investigated results of an experimental study on the strength and absorption characteristics of Geopolymer concrete. In this experiment Total nine mixes were prepared with $\mathrm{NaOH}$ concentration as $8 \mathrm{M}, 12 \mathrm{M}, 16 \mathrm{M}$ and curing time as $24 \mathrm{hrs}, 48 \mathrm{hrs}$, and $72 \mathrm{hrs}$. Compressive strength, water absorption and tensile strengths tests were conducted on each of the nine mixes. Results of the investigation indicated that there was an increase in compressive strength with increase in $\mathrm{NaOH}$ concentration. Strength was also increased with increase in curing time, although the increase in compressive strength after $48 \mathrm{hrs}$ curing time was not significant. Compressive strength up to $46 \mathrm{MPa}$ was obtained with curing at $60^{\circ} \mathrm{C}$. The results of water absorption test indicated that $\%$ water absorption of cubes decreased with increase in $\mathrm{NaOH}$ concentration and curing time.

Parthiban Shobana [3] and his fellows investigate the Chemical Admixture does not show any impact on Compressive Strength but shows considerable increase in 
the workability of the concrete. The Specimens have been cured in ambient temperature condition to check the suitability of Geopolymer concrete for cast-in-situ conditions. 7 day strength was found to be $70 \%$ of its 28 days strength, the 28 days strength is higher compared to OPC.

Ganapati, Adhiseshu [4] and his fellows investigate replacement of Fly ash for 5 different GGBS content (upto $40 \%$ ) and $8 \mathrm{M} \mathrm{NAOH}$ solution and NA2SIO3/NAOH ratio was 2.5 taken and the result indicates that with the increase of Slag content, the compressive Strength of 31.85 at 3 days achieved. From the paper it is also concluded that there is no necessity of Exposing Geopolymer Concrete to Higher temperature to attain maximum Strength if minimum $9 \%$ of flyash is replaced by GGBS. 90\% of compressive Strength was achieved in 14 days and the average density of Geopolymer. Concrete was equal to that of OPC concrete.

Partha, Prabir and Pradip [5] investigated that the GGBS added to (0 to $20 \%$ ) of total binder, significant increase in Strength and some decrease in workability observed on Geopolymer concrete. The addition of GGBFS enhanced setting of the concrete at ambient temperature. The strength gain slowed down after the age of 28 days and continues to increase at a slower rate until 180 days. The effect of mixture variables on the development of tensile strength was similar to that on the development of compressive strength.

Supraja and Kantarao [6] investigated that in order to produce GGBS added Geopolymer concrete different Molarities 3M, 5M, 7M and $9 \mathrm{M}$ are taken to prepare different mixes. The Cube Specimens are taken of $100 \mathrm{~mm} * 100 \mathrm{~mm} * 100 \mathrm{~mm}$. Two different curing are carried oven curing at 50C and Direct Sunlight Curing. The Result shows that there is no significant increase in strength of oven cured specimens after 3 days of Geopolymer concrete and the strength of Geopolymer concrete is increasing with the increase of the morality of Sodium Hydroxide. Sunlight curing is more convenient for practical conditions

Madheshwaran, Gnansundar, Gopalkrishnan [7] investigated the The variation of GGBFS in concrete has been studied and Longer curing time improved the Polymerization process and results in compressive Strength. Higher the Molar Ratio (7 M) with Higher GGBS (100\%)results in the Higher Compressive Strength and Split tensile strength .By this compressive Strength in the range of $45 \mathrm{Mpa}$ to $60 \mathrm{Mpa}$ is achieved and Highest is for $100 \%$ GGBS. Apart from energy intensiveness, the GPCs utilize the industrial waste for producing the binding system in concret, there are both environment and Economical Benefits of Using Fly ash and GGBS. The addition of Naphthalene based Super Plasticizer content more than $2 \%$ slightly reduce the Compressive Strength.

Ravindra and Somnath [8] investigated that with the Increase of silica content in flyash, the size of Spherical shaped unreacted fly ash particles in the Geopolymer matrix indicating formation of more aluminosilicate gel which results in the increased compressive strength. When the silica content beyond 4 by (Sio2/A12o3) leads to reduction in reactivity and decrease in Strength while lower water content in the mix, Higher was the Compressive Strength. Filler Material like Sand Reduces cracking and improves the porosity of the Composite and its addition also reduces the quantity of Binder paste making the material more economical. The Setting time of Geopolymer is also longer at Higher Silica content.

Pradip and Prabir [9] investigated the Fly ash Geopolymer mixtures were designed adding GGBFS upto $30 \%$ of total Binder and curing is at ambient Temperature. By adding 30\% GGBFS Compressive Strength about 55 Mpa has been achieved.The compactness of the Gel increased when Slag Content is higher in the paste.

Matghew Sudhakar and Natarajan [10] investigated that with the increase of GGBS content, Compressive Strength is gradually increases in this Coal Ash and GGBS Combination is taken along with $15 \mathrm{M}$ Alkaline Solution and total replacement of about $30 \%$ is taken into consideration and Higher Compressive Strength up to 57Mpa is achieved .However the Cost of GGBS added Geopolymer is 7\% Higher than OPC but when we Consider Strength aspect, it is almost 3 times than OPC at 7 days.

\section{DISCUSSION}

Based on various researchers, it is observed that Geopolymer Concrete made up of Fly ash and Alkaline Solution Provides, a new era In the Construction Industry. Sodium Silicate $\left(\mathrm{Na}_{2} \mathrm{SiO}_{3}\right)$ and Sodium Hydroxide $(\mathrm{NaOH})$ when reacts with fly ash generates Geopolymerization Process and which is responsible for the Strength generation. Geopolymer Concrete Requires Oven Curing of $60^{\circ} \mathrm{C}$ to $100^{\circ} \mathrm{C}$ for 24 to 96 Hours. GGBS makes significant impact on the strength of Geopolymer concrete.

\section{CONCLUSION}

Based upon above literature review it could be concluded that all researchers have put their efforts to show the effect of GGBS on Geopolymer Concrete. However it should be noted that with the variation in the perameters such as $\mathrm{Na}_{2} \mathrm{SiO}_{3} / \mathrm{NaOH}$ Ratio, Molarity of $\mathrm{NaOH}$, Curing temperature, Curing time makes the Variation in the Strength. Replacement of Flyash by GGBS increases the Strength gradually without Oven curing provision. However oven cured Cubes shows higher Compressive and tensile strength than that of ambient temperature cured cubes. So by using GGBS content we can remove the Problem of oven curing provision.

\section{REFERENCES}

[1]. Palomo, M.W.Grutzeck, M.T.Blanco "Alkali-activated fly ashes -A cement for the future ",Elsevier,1998,Volume 29, Issue 8, page 1323-1329.

[2]. Anurag Mishra, Deepika Choudhary, Namrata Jain, Manish Kumar, Nidhi Shardaand Durga Dutt, "Effect of 
Concentration of Alkaline Liquid and Curing Time on Strength and Water Absorption of Geopolymer Concrete", ARPN Journal ,2008, ISSN-1819-6008,Page 14-18.

[3]. K.Parthiban, K.saravanarajamohan, S.Sobana, A.Anchal Bhaskar, "Effect of Replacement of Slag on the Mechanical Properties Of Fly ash based Geopolymer Concrete", International Journal of Engineering and Technology (IJET),2013, ISSN: 0975-4024, Page 2555-2559

[4]. Ganapati Naidu, A.S.S.N. Prasad, S. Adiseshu , P.V.V.satayanaray "A study on strength properties of Geopolymer Concrete with the addition of GGBS ",International Journal of Engineering Research and Development (IJERD),2012 ISSN: 2278-800, Page 19-28

[5]. Partha Sarathi Deb,Pradip Nath, Prabir kumar sarker, "The Effects of GGBFS blending with Flyash and activator content on the workability and strength properties of Geopolymer concrete cured at ambient temperature ", Elsevier, Material and design,62(2014),page 32-39

[6]. V.supraja , M.kantarao , "Experimental study on Geopolymer concrete incorporating GGBS", International Journal of Electronics, Communications and Self Computing Science and Engineering (IJECSCSE), 2012 , ISSN : 2277-9477, Page 11-15

[7]. Madheswaran C.K,Gnansundar G, Gopalkrishnan, "Effect of molarity in Geopolymer concrete", International Journal of Civil and Structural Engineerimg, ISSN 09764399, Vol. 4, No. 2, 2013 page 106-115

[8]. Ravindra N.Thakur, Somnath Ghosh, "Effect of mix composition on compressive strength and microstructure of flyash based Geopolymer Concrete", ARPN Journal of Engineering and Applied Sciences, Vol4, No 4, June 2009, ISSN 1819-6608, page 68-71

[9]. Pradip Nath,Prabir kumar Sarker "Effect of GGBFS on Setting, Workability and early Strength properties of flyash Geopolymer Concrete ", Elsevier, construction and building materials, 2014 , 66, page 163-171

[10]. Mr. Bennet Jose Mathew, Mr. M Sudhakar, Dr. C Natarajan, "Strength, Economic and Sustainability Characteristics of Coal Ash -GGBS Based Geopolymer Concrete", International Journal Of Computational Engineering Research (ijceronline),ISSN 2250-3005 Vol. 3 Issue. 1,page 207-212

\section{BIOGRAPHIES}

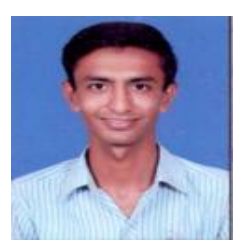

Paras Sureshbhai Pithadiya was born in 1991 in Rajkot, Gujarat. He receives his Bachelor of Engineering degree in Civil Engineering from R.K. College of Engineering and Technology, Gujarat Technological University in 2013. At present he is Final year student of Master's degree in Structural engineering from Marwadi Education Foundation Group of Institutions, Gujarat Technological University.

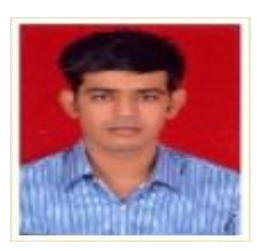

Prof. Abhay V. Nakum was born in 1990 in Jamkhambhaliya, Gujarat. $\mathrm{He}$ received his Bachelor of Engineering degree from L. D. Engineering College, Gujarat University in 2011. In 2013 he received his Master's Degree in
Structural Engineering from Marwadi Education Foundation Group of Institutions, Gujarat Technological University. He joined Marwadi Education Foundation Group of Institutions as a Assistant Professor of Civil Engineering Department. He has paper published in International Journal. 